\title{
Efficacy, safety, and tolerability of travoprost $0.004 \%$ BAK-free versus prior treatment with latanoprost $0.005 \%$ in Japanese patients
}

This article was published in the following Dove Press journal:

Clinical Ophthalmology

22 November 2010

Number of times this article has been viewed

\author{
Michael J Miyashiro' \\ Samuel C Lo ${ }^{2}$ \\ Jeanette A Stewart ${ }^{3}$ \\ William C Stewart ${ }^{3}$ \\ 'Ludwig Ophthalmology Centre, Hilo, \\ HI, USA; ${ }^{2}$ Private Practice, Honolulu, \\ HI, USA; ${ }^{3}$ PRN Pharmaceutical \\ Research Network, LLC, Dallas, TX, \\ USA
}

Objective: To examine the efficacy, safety, and tolerability of travoprost $0.004 \%$ benzalkonium chloride (BAK)-free compared with previous use of latanoprost $0.005 \%$ in Japanese patients living in the US who had primary open-angle glaucoma or ocular hypertension.

Methods: This was an open-label, multicenter, bilateral, intraindividual, and active-controlled study in which 20 Japanese American patients with primary open-angle glaucoma or ocular hypertension who had been on latanoprost $0.005 \%$ monotherapy were changed to monotherapy with travoprost $0.004 \%$ BAK-free daily for 12 weeks. Patients were administered the same series of tests to evaluate the efficacy, safety, and tolerability of latanoprost at the baseline visit and of travoprost BAK-free at the week 12 visit.

Results: No significant difference in mean intraocular pressure (IOP) was observed between latanoprost monotherapy at baseline and travoprost BAK-free monotherapy after 12 weeks $(P=0.76)$, nor were significant differences noted in mean ocular hyperemia, visual acuity, corneal fluorescein staining, or overall scores from the Ocular Surface Disease Index. Patients had a significantly shorter mean tear breakup time while on latanoprost compared with travoprost BAK-free $(P=0.0094)$. Significantly more patients preferred travoprost BAK-free monotherapy over latanoprost monotherapy (14 versus $6 ; P=0.011$ ).

Conclusion: The results of this study suggest that Japanese American patients transitioned from latanoprost $0.005 \%$ monotherapy to travoprost $0.004 \%$ BAK-free can expect similar IOP control and some improvement in anterior segment signs. This transition study showed a strong patient preference for travoprost BAK-free over latanoprost, at a ratio of more than 2:1.

Keywords: glaucoma, intraocular pressure, latanoprost, prostaglandin analog, travoprost

\section{Introduction}

Prostaglandin analogs are among the most common first-line therapies for the treatment of elevated intraocular pressure (IOP) associated with glaucoma. Because glaucoma is a chronic disease, the long-term safety of prostaglandin analogs is of paramount importance. However, many prostaglandin analogs contain preservatives that may be toxic to the eye. ${ }^{1}$ The most common preservative in IOP-lowering medications is benzalkonium chloride (BAK), a quaternary ammonium compound that causes bacterial cell death by lysing cytoplasmic membranes. ${ }^{2}$ BAK has demonstrated toxicity against both corneal and conjunctival cells when administered in the range of concentrations present in ophthalmic medications $(0.004-0.02 \%) .^{2-5}$ Moreover, in vitro, animal, and clinical studies have demonstrated that BAK-containing medications are associated with greater toxicity, increased ocular surface damage, and decreased tolerability compared with BAK-free preparations. ${ }^{6-10}$ Latanoprost $0.005 \%_{\text {(Xalatan }}^{\circledR}$; Pfizer Inc., New York, NY) 
contains $0.02 \% \mathrm{BAK}$, one of the highest BAK concentrations found in ophthalmic preparations. Instead of using BAK as a preservative, travoprost $0.004 \%$ BAK-free (Travatan $Z^{\circledR}$; Alcon Laboratories, Inc., Fort Worth, TX) contains the alternative preservative system SofZia ${ }^{\mathrm{TM}}$, containing borate, zinc, and sorbitol. ${ }^{9}$ Although limited research has been published on SofZia ${ }^{\mathrm{TM}}$, a relatively new preservative, available studies report no significant difference in ocular toxicity between travoprost BAK-free and preservative-free artificial tears. ${ }^{8,9}$

Both in vitro and in vivo studies directly comparing travoprost BAK-free with latanoprost show that travoprost BAK-free is less toxic to the cornea and conjunctiva. ${ }^{6-8,11}$ In addition, a transition study by Horsley and Kahook ${ }^{10}$ also reported that patients with reduced tear breakup time who transitioned to travoprost BAK-free monotherapy after at least one year of latanoprost monotherapy had decreased corneal staining, longer tear breakup time, and fewer ocular surface disease symptoms, while maintaining equivalent IOPlowering efficacy. We were interested to determine whether these favorable outcomes noted with travoprost BAK-free would be duplicated in Japanese patients, a population that is generally underrepresented in clinical studies but is prevalent on the island of Hawaii. Therefore, the goal of the current study was to examine the efficacy, safety, and tolerability of travoprost $0.004 \%$ BAK-free compared with previous use of latanoprost $0.005 \%$ in Japanese patients with primary openangle glaucoma or ocular hypertension living in the US.

\section{Methods}

This was a prospective, open-label, multicenter, intraindividual, and active-controlled study. The objective of the study was to examine the safety, efficacy, and tolerability of travoprost BAK-free in Japanese patients on prior latanoprost monotherapy. The protocol was approved by all relevant institutional review boards and the study was performed in compliance with the ethical principles of the Declaration of Helsinki and Good Clinical Practice. All participating patients provided written informed consent.

\section{Patients}

Eligible patients were at least 21 years old with a clinical diagnosis of primary open-angle glaucoma or ocular hypertension in at least one eye (and a documented history of untreated IOP $>21 \mathrm{mmHg}$ ) and were of Japanese origin. Japanese origin was defined as descended from both maternal and paternal Japanese grandparents and Japanese parents (one parent could be half-Japanese), and part of the third generation or younger to live in the US. They also needed to have been treated with latanoprost monotherapy for at least one week prior to enrollment and had to have an IOP $\geq 16 \mathrm{mmHg}$ in at least one eye and $\leq 30 \mathrm{mmHg}$ in both eyes at the baseline visit. They were required to have a best corrected Snellen visual acuity (BCVA) of at least 20/200 in both eyes, and the investigator had to consider the patient a good candidate for travoprost BAK-free due to a need for improved tolerability or reduced IOP over that observed with latanoprost therapy.

Patients were excluded if they met any of the following criteria: presence or untreated history of narrow angles with or without complete or partial closure in either eye; any abnormality preventing reliable applanation tonometry in a study eye; any known opacity or patient uncooperativeness that restricted adequate examination of the ocular fundus or anterior chamber of either eye; concurrent infectious/noninfectious conjunctivitis, keratitis, scleritis, blepharitis, or uveitis in either eye; conventional intraocular surgery within three months prior to screening or laser surgery within two months prior to screening in either eye; history of ocular trauma within six months prior to screening; risk of visual field or visual acuity worsening as a consequence of trial participation, in the investigator's opinion; progressive retinal or optic nerve disease from any cause other than glaucoma; women who were pregnant, lactating, or of childbearing potential and not using a reliable means of birth control; any clinically significant, serious, or severe medical or psychiatric condition or severe dementia; any condition which, in the opinion of the principal investigator, would interfere with optimal participation in the study or present a special risk to the patient; participation in any other investigational study within 30 days prior to visit 1 ; known history of allergy, sensitivity or poor tolerance to any components of the study medications; use of systemic medications known to affect IOP, which have not been on a stable course for seven days prior to visit 2 or an anticipated change in the dosage during the course of the study; unwillingness to risk the possibility of darkened irides, eyelash changes, or periocular pigmentation; history or risk of uveitis or cystoid macular edema; history of ocular herpes simplex; anticipated use of ocular, dermal, or oral corticosteroids for more than two weeks in total during the trial or current chronic use of ocular, dermal, or oral corticosteroids; and use of contact lenses in the study eye(s). Both eyes of eligible patients could be enrolled if both met the inclusion and exclusion criteria.

\section{Study design}

Patients who were eligible for trial participation after screening were continued on latanoprost monotherapy for one additional week until the baseline visit. At the baseline visit, patients were asked to complete the validated Ocular Surface Disease Index (OSDI) questionnaire. ${ }^{12}$ The OSDI was developed by 
the Outcomes Research Group at Allergan, Inc. (Irvine, CA) to provide a rapid assessment of the severity of symptoms of ocular surface disease and their impact on vision-related function. ${ }^{13}$ OSDI scores were classified as normal (0-12), mild ocular surface disease symptoms (13-22), moderate ocular surface disease symptoms (23-32), and severe ocular surface disease symptoms (33-100), as previously described. ${ }^{14}$ Evaluations conducted at the baseline visit included BCVA, ocular hyperemia grading, slit-lamp biomicroscopy, tear breakup time, corneal fluorescein staining, and Goldmann applanation tonometry at $4 \mathrm{pm}$. The patients were then changed from BAK-preserved latanoprost monotherapy to travoprost ophthalmic solution $0.004 \%$ BAK-free administered once daily at $8 \mathrm{pm}$ for 12 weeks. Patients returned to the clinic at week 4 for a safety assessment (BCVA, slit-lamp biomicroscopy, and IOP at $4 \mathrm{pm}$ ) and at week 12 to undergo final study visit evaluations (same as for baseline visit) and to answer a study medication preference question. Adverse events were collected, monitored, and evaluated throughout the study.

\section{Statistics}

The primary efficacy variable was the change in IOP from latanoprost monotherapy at the baseline visit to travoprost BAK-free monotherapy at the week 12 visit and was analyzed by a two-tailed paired $t$-test. A two-tailed paired $t$-test was also utilized to evaluate differences in hyperemia, tear breakup time, corneal fluorescein staining, ocular surface disease patient questionnaire, and visual acuity. Adverse events and patient preference were analyzed by a McNemar test. An intent-to-treat average eye analysis was used. An $\alpha$-level of 0.05 was used to declare statistical significance. The data were analyzed by the PRN Pharmaceutical Research Network, LLC (Dallas, TX).

\section{Results}

Twenty Japanese American patients were enrolled and evaluable for analysis. As shown in Table 1, patients had a mean age of $73.1 \pm 9.8$ years and nearly all (95\%) had a diagnosis of primary open-angle glaucoma. Nineteen patients received latanoprost for one month or less before transitioning to travoprost BAK-free and the one remaining
Table I Patient demographics*

\begin{tabular}{ll}
\hline Mean age (years \pm standard deviation) & $73.1 \pm 9.8$ \\
Gender $(\mathrm{n}, \%)$ & $9(45 \%)$ \\
Male & $1 \mathrm{I}(55 \%)$ \\
Female & \\
Ophthalmic history $(\mathrm{n}, \%)$ & $19(95 \%)$ \\
Primary open-angle glaucoma & $\mathrm{I}(5 \%)$ \\
Ocular hypertension & $\mathrm{I}(5 \%)$ \\
Cataract & $\mathrm{I}(5 \%)$ \\
\hline Epiretinal membrane &
\end{tabular}

Note: *Two patients with primary open-angle glaucoma also had cataract or epiretinal membrane.

patient received latanoprost for approximately six weeks. No significant difference in mean IOP was observed between latanoprost monotherapy at baseline and travoprost BAKfree monotherapy after 12 weeks $(17.0 \pm 1.5 \mathrm{mmHg}$ versus $17.1 \pm 1.6 \mathrm{mmHg}, P=0.76$, Table 2 ) nor were significant differences noted in mean ocular hyperemia $(0.7 \pm 0.8$ versus $0.3 \pm 0.4, P=0.064)$. Patients had a significantly shorter mean tear breakup time while on latanoprost monotherapy compared with travoprost BAK-free monotherapy $(7.6 \pm 3.2 \mathrm{sec}$ versus $9.5 \pm 2.3 \mathrm{sec}, P=0.0094)$. An examination of safety parameters revealed no significant changes in visual acuity, corneal staining, or slit-lamp biomicroscopy.

Mean OSDI scores were normal at baseline when patients were receiving latanoprost monotherapy and remained in the normal range (0-12) after 12 weeks on travoprost BAK-free. Three adverse events were reported during the study, including one case each of inferior superficial punctate epithelial erosion, corneal stippling, and increased ocular redness and dryness. The patient experiencing increased ocular redness and dryness discontinued the study. This adverse event was the only one classified as related to treatment. Significantly more patients preferred travoprost BAK-free monotherapy compared with latanoprost monotherapy (14 versus $6, P=0.011$ ).

\section{Discussion}

Patients with glaucoma are particularly susceptible to BAK-induced ocular toxicity because they take BAKcontaining medications chronically, often for decades. In both conjunctival and corneal cells, BAK has been found to induce apoptosis ${ }^{5,7}$ and increase proinflammatory cytokine

Table 2 Mean efficacy and safety measures of latanoprost monotherapy versus travoprost BAK-free monotherapy

\begin{tabular}{lll}
\hline Measure* & Latanoprost & Travoprost BAK-free \\
\hline Intraocular pressure (mmHg) & $17.0 \pm 1.5$ & P value \\
Tear film breakup time (sec) & $7.6 \pm 3.2$ & 0.76 \\
Ocular hyperemia (scale of 0-3) & $0.7 \pm 0.8$ & $9.5 \pm 2.3$ \\
Visual acuity (Snellen) & $27.9 \pm 8.5$ & $0.3 \pm 0.4$ \\
\hline
\end{tabular}

Note: *All scores are presented as mean \pm standard deviation.

Abbreviation: BAK, benzalkonium chloride. 
elaboration. ${ }^{15}$ BAK can also produce corneal microvilli loss, ${ }^{8}$ conjunctival lymphocyte infiltration, ${ }^{8}$ and conjunctival goblet cell loss. ${ }^{9}$ Clinical studies have supported the hypothesis that BAK-containing ophthalmic medications are detrimental to ocular surface health. ${ }^{8-10,16}$

In the current study, patients had a mean increase of almost two seconds in tear breakup time after 12 weeks of travoprost BAK-free monotherapy $(P=0.0094)$. A potential explanation for this significant improvement may be provided by the fact that BAK-containing latanoprost has been reported to produce a loss in conjunctival goblet cells, which has not been observed with travoprost BAK-free. ${ }^{9}$ Because goblet cells facilitate ocular surface wettability and tear film stability through the secretion of mucin, ${ }^{17}$ a loss of these cells would be expected to destabilize the tear film, leading to decreased tear breakup time. The Horsley study, which compared latanoprost with travoprost BAK-free and had a study design similar to the current study, also reported a significant increase in tear breakup time after transition to travoprost BAK-free $(P<0.001),{ }^{10}$ supporting the results of our study.

Patients in the current study were found to have no significant changes in IOP 12 weeks after transitioning from latanoprost monotherapy to travoprost BAK-free monotherapy, suggesting that the removal of BAK does not affect IOP control. With respect to safety, patients had no significant changes in visual acuity, corneal staining, or slit-lamp biomicroscopy. An examination of ocular hyperemia demonstrated a trend toward less hyperemia with travoprost BAK-free, but missed statistical significance $(P=0.064)$ due to the small number of patients. This is noteworthy, because studies of latanoprost and BAK-containing travoprost have demonstrated a modest increase in the incidence and severity of hyperemia with travoprost relative to latanoprost. ${ }^{18-20}$ Results from this study suggest that travoprost BAK-free may not have an ocular hyperemia disadvantage, although the relatively small sample size of this study ( $n=40$ eyes) may make a modest difference difficult to detect. However, the Horsley study comparing latanoprost and travoprost BAK-free did demonstrate a significant improvement in corneal staining after transition to travoprost BAK-free $(P<0.001) .{ }^{10}$ While no definitive conclusions can be drawn regarding the discrepancy between our results and those of Horsley and Kahook, the fact that patients in the Horsley study had been on latanoprost therapy for at least a year may have contributed to the different results. In the current study, most patients received latanoprost for less than a month, and because corneal damage from BAK is cumulative, corneal staining would most likely not be affected after only a few weeks of BAK exposure.
Additionally, our study design did not select for patients with ocular surface disease. The patients entered the study with normal OSDI scores and ocular staining and, as expected, no changes were observed after 12 weeks of dosing with the travoprost BAK-free formulation.

The brief duration of latanoprost therapy ( $\leq$ six weeks) prior to transitioning to travoprost BAK-free is a limitation of this study because it may not have allowed enough time to observe differences in IOP and/or adverse effects between treatments. A similar study with a longer requirement for latanoprost use prior to transition might produce differences in other parameters that were not evident in the current study. However, the fact that the Japanese patients in this study had a strong preference for travoprost BAK-free after such a short time taking latanoprost suggests strongly that patients perceived travoprost BAK-free to be more tolerable than latanoprost.

In conclusion, this study, albeit in a limited number of patients, demonstrates that patients of Japanese origin with primary open-angle glaucoma or ocular hypertension can be changed from latanoprost $0.005 \%$ monotherapy to travoprost 0.004\% BAK-free monotherapy, with similar IOP control and similar or improved safety and tolerability. Based on these results, it is appropriate to expect that patients would view such a transition favorably.

\section{Acknowledgment}

Jennifer Klem, PhD provided medical writing assistance, which was funded by Alcon Laboratories, Inc.

\section{Disclosure}

The authors report no conflicts of interest in this work.

\section{References}

1. Epstein SP, Ahdoot M, Marcus E, Asbell PA. Comparative toxicity of preservatives on immortalized corneal and conjunctival epithelial cells. J Ocul Pharmacol Ther. 2009;25(2):113-119.

2. Noecker R. Effects of common ophthalmic preservatives on ocular health. Adv Ther. 2001;18(5):205-215.

3. de Saint Jean M, Brignole F, Bringuier AF, Bauchet A, Feldmann G, Baudouin C. Effects of benzalkonium chloride on growth and survival of Chang conjunctival cells. Invest Ophthalmol Vis Sci. 1999;40(3): 619-630.

4. Debbasch C, Pisella PJ, de Saint JM, Rat P, Warnet JM, Baudouin C. Mitochondrial activity and glutathione injury in apoptosis induced by unpreserved and preserved beta-blockers on Chang conjunctival cells. Invest Ophthalmol Vis Sci. 2001;42(11):2525-2533.

5. Sosne G, Albeiruti AR, Hollis B, Siddiqi A, Ellenberg D, KurpakusWheater M. Thymosin beta4 inhibits benzalkonium chloride-mediated apoptosis in corneal and conjunctival epithelial cells in vitro. Exp Eye Res. 2006;83(3):502-507.

6. Yee RW, Norcom EG, Zhao XC. Comparison of the relative toxicity of travoprost $0.004 \%$ without benzalkonium chloride and latanoprost $0.005 \%$ in an immortalized human cornea epithelial cell culture system. Adv Ther. 2006;23(4):511-519. 
7. Baudouin C, Riancho L, Warnet JM, Brignole F. In vitro studies of antiglaucomatous prostaglandin analogues: Travoprost with and without benzalkonium chloride and preserved latanoprost. Invest Ophthalmol Vis Sci. 2007;48(9):4123-4128.

8. Kahook MY, Noecker RJ. Comparison of corneal and conjunctival changes after dosing of travoprost preserved with sofZia, latanoprost with $0.02 \%$ benzalkonium chloride, and preservative-free artificial tears. Cornea. 2008;27(3):339-343.

9. Kahook MY, Noecker R. Quantitative analysis of conjunctival goblet cells after chronic application of topical drops. Adv Ther. 2008;25(8): 743-751.

10. Horsley MB, Kahook MY. Effects of prostaglandin analog therapy on the ocular surface of glaucoma patients. Clin Ophthalmol. 2009;3: 291-295.

11. Nagai N, Murao T, Okamoto N, Ito Y. Comparison of corneal wound healing rates after instillation of commercially available latanoprost and travoprost in rat debrided corneal epithelium. J Oleo Sci. 2010;59(3):135-141.

12. Schiffman RM, Christianson MD, Jacobsen G, et al. Reliability and validity of the Ocular Surface Disease Index. Arch Ophthalmol. 2000 118(5):615-621.

13. Walt JG, Rowe MM, Stern KL. Evaluating the functional impact of dry eye: The Ocular Surface Disease Index. Drug Inf J. 1997;31:1436.
14. Rossi GC, Tinelli C, Pasinetti GM, et al. Dry eye syndrome-related quality of life in glaucoma patients. Eur J Ophthalmol. 2009;19(4):572-579.

15. Epstein SP, Chen D, Asbell PA. Evaluation of biomarkers of inflammation in response to benzalkonium chloride on corneal and conjunctival epithelial cells. J Ocul Pharmacol Ther. 2009;25(5):415-424.

16. Fechtner RD, Godfrey DG, Budenz D, et al. Prevalence of ocular surface complaints in patients with glaucoma using topical intraocular pressure-lowering medications. Cornea. 2010;29(6):618-621.

17. Gipson IK. Distribution of mucins at the ocular surface. Exp Eye Res. 2004;78(3):379-388.

18. Netland PA, Landry T, Sullivan EK, et al; Travoprost Study Group. Travoprost compared with latanoprost and timolol in patients with openangle glaucoma or ocular hypertension. Am J Ophthalmol. 2001;132(4): 472-484.

19. Parrish RK, Palmberg P, Sheu WP; XLT Study Group. A comparison of latanoprost, bimatoprost, and travoprost in patients with elevated intraocular pressure: A 12-week, randomized, masked-evaluator multicenter study. Am J Ophthalmol. 2003;135(5):688-703.

20. Stewart WC, Kolker AE, Stewart JA, Leech J, Jackson AL. Conjunctival hyperemia in healthy subjects after short-term dosing with latanoprost, bimatoprost, and travoprost. Am J Ophthalmol. 2003;135(3): 314-320.
Clinical Ophthalmology

\section{Publish your work in this journal}

Clinical Ophthalmology is an international, peer-reviewed journal covering all subspecialties within ophthalmology. Key topics include: Optometry; Visual science; Pharmacology and drug therapy in eye diseases; Basic Sciences; Primary and Secondary eye care; Patient Safety and Quality of Care Improvements. This journal is indexed on

Submit your manuscript here: http://www.dovepress.com/clinical-ophthalmology-journal

\section{Dovepress}

PubMed Central and CAS, and is the official journal of The Society of Clinical Ophthalmology (SCO). The manuscript management system is completely online and includes a very quick and fair peer-review system, which is all easy to use. Visit http://www.dovepress.com/ testimonials.php to read real quotes from published authors. 